\title{
Mediterranien cuttlefish sepia officinalis squid ink is cytotoxic but does not inhibit Glioblastoma U87 tumor cells proliferation, with high nutritional values of edible viscera
}

\author{
Soufia Chabchoub Ellouze ${ }^{13 *}$, Hazem Ben Mabrouk ${ }^{1}$, Olfa Baroudi $^{2}$, Naceur Ayed ${ }^{4}$, Naziha Marrakchi ${ }^{1}$ \\ ${ }^{1}$ Tunis El-Manar University: Laboratory of Venoms Biomolecules and Therapeutics, Institute Pasteur Tunis Tunisia \\ ${ }^{2}$ Tunis El-Manar University: Genetics, Immunology and Human Pathology Laboratory. Faculty of Sciences Tunis Tunisia \\ ${ }^{3}$ Tunis El-Manar University:Higher Institute of Medical Biotechnology Tunis Laboratory of Biophysics and Medical Technology \\ ${ }^{4}$ Carthage University: Research Unit of organic and alimentary chemical industry INSAT National Institute of Applied Science and \\ technology, Tunis, Tunisia \\ *Corresponding author E-mail: soufiaellouzchabchoub@yahoo.fr
}

Copyright $\odot 2014$ Soufia Chabchoub Ellouze et al. This is an open access article distributed under the Creative Commons Attribution License, which permits unrestricted use, distribution, and reproduction in any medium, provided the original work is properly cited.

\begin{abstract}
This study aims to identify nutritional values of some viscera's cuttlefish Sepia officinalis commonly edible in Tunisia (Nidamental gland, hepatopancreas, male gonad, squid ink) and to evaluate the role of cuttlefish ink, on viability and proliferation of human glioblastoma cells U87.Biochemical analysis shows that solid and liquid viscera are rich in water, in Protein and in total Ash. They contain less fat and Carbohydrates. Energy values are substantial. Sex and Cooking over low have no significant effect on these nutritional values. These results lead us to encourage the use of these marine co-products (generally rejected), not only for food but for prevent and reduce the incidence of certain diseases. In fact our results show also a cytotoxic effect of cuttlefish ink at increasing doses on human cells cancer Glioblastoma U87 for an incubation time of 5 hours with a concentration higher than $20 \mu \mathrm{g} / \mathrm{ml}$. The IC 50 value is $25 \mu \mathrm{g} / \mathrm{ml}$ which may be due to tyrosinase, responsible for the cephalopod ink toxic. Supernatant of cuttlefish ink Sepia offinalis does not block proliferation of cancer cells U87 during 4 days of incubation. Further analyses are warranted and necessary to substantiate and complete our findings such as the study of the effect of this ink in adhesion and migration of Glioblastoma cells U87.
\end{abstract}

Keywords: Edible Viscera, Cuttlefish Sepia Officinalis, Supernatant Cuttlefish Ink, Nutritional Values, Viability, Proliferation, Human Glioblastoma U87.

\section{Introduction}

Seas and oceans considered as the origin of life are a single source of natural products sea food (fishes, shellfishes, mollusks, algae and others) [1]. These products can be eaten fresh, dried, salted, frozen or processed [2]. Among these marine products cuttlefish is very popular in European, Chinese and Tunisian markets. One of the major transformations of this resource is the packaging of fresh or frozen for export of several co-products: solid (head, skin, viscera) and liquid (squid ink). Actual environmental policy encourages more manufacturers to take into account the waste generated by any process of transformation. It became so important to find ways of scientific value of these coproducts while incorporating the concept of sustainable development. Currently the co-products, poorly valued are essentially processed into meal and oil, intended primarily for animal feed [3-4]. Working on capelin fish [5], on the shark [6], these others showed that heads, bones, guts and skins are an important source of proteins and essential amino acids and have a significant nutritional value. Food markets, pharmaceutical or cosmetics could accommodate such as fishery products. Like fish, cuttlefish has great nutritional value. This is one of the most protein-rich marine species. If the visceral mass of fish has been extensively studied over the past 20 years, those of cephalopods have been until recently little worked. Some researchers are interested in the development of squid hepatopancreas [7], [8], other in the quality of viscera of cuttlefish Sepia officinalis and its digestive gland [9]. Squid ink (liquid co-product), is also a 
traditional medicine reamed used often as a treatment for heart disease, gynecology and surgery [6]. It contains alarm indices: uridine, cytidine and uracil [7]. It is a metabolic inhibitor on other organisms [8]. As biological properties, it has been shown that cuttlefish ink could induce bone marrow cells to form colonies in vitro that lead to an increase in the number of leukocytes [9]. It can activate the LT and LB Lymphocyte cells and inhibit bacteria particularly Psychotrophe flora [10-11]. It can also inhibit proliferative properties studied on chicken embryo fibroblasts in vitro [12].

Falling within the general framework of valorization co-mollusk products, this work, first aims to identify the nutritional values of some viscera cuttlefish Sepia officinalis for: nidamental gland, hepatopancreas, male gonad and squid ink. These organs are generally edible form of sauce or soup in some regions of Tunisia: Sfax, Kherkena, Bizerte, Gabes and Zarzis. In the second part, we try to study the effect of supernatant cuttlefish ink on cytotoxicity and proliferation on cancer cells Gluoblastoma U87.

\section{Material and methods}

\subsection{Biological material}

Cuttlefish Sepia officinalis (Linné, 1753) is a cephalopod mollusk belonging to the family of Sepiidaes, gender and species Sepia officinalis.

Cuttlefish is captured from the coastal region Kalaat El Andalo (North East of Tunisia), by fishing nets trammel diameter $35 \mathrm{~cm}$. Animals are washed with sea water and kept on ice. Back in the laboratory morph metric parameters considered as a reference size adults, are measured using an electronic caliper. Sex determination is due to the dissection of the squid which allows us to carefully remove nidamental glands, hepatopancreas, male gonad and ink black pocket, immediately emptied. Forty of each co-product is collected in a $50 \mathrm{ml}$ Falcon tube. Half is stored at $-20^{\circ} \mathrm{C}$ for possible nutritional analysis of each organ as follows: (relative humidity, total ash, fat, protein, carbohydrates and energy value). Ach half is braised. It undergoes a cooking slowly and evenly covered in 3 to $5 \mathrm{ml}$ of distilled water according to the organ to cook.

This water over low heat for 15 minutes (temperature between $60-70^{\circ} \mathrm{C}$ ). The organ is cooled then put in another Falcon tube and stored at $-20^{\circ} \mathrm{C}$ for later subject the same nutritional analysis that fresh uncooked organs.

\subsection{Methods of measurement of nutritional values}

Measures of nutritional values were performed using the following methods: relative humidity (baking at $105^{\circ} \mathrm{C}$ for $4 \mathrm{H}$ ), total ash (ignition at $900^{\circ} \mathrm{C}$ for 2 hours), fat (Folch et al method) [13], proteins (Crooke et al method) [14]. Carbohydrate and energy values were determined by simple calculation.

\subsection{Protein extraction}

The first step is a mechanical grinding of the product in liquid nitrogen. Then we use a protein precipitation step in acetone $-30^{\circ} \mathrm{C} 2$ volumes overnight [15]. Subsequently, the supernatant is collected after centrifugation (2000 rpm) and lyophilized. The lyophilized product re-suspended in $1 \mathrm{ml}$ of distilled $\mathrm{H}_{2} \mathrm{O}$.

\subsection{Protein quantification}

The protein was estimated using Pierce BCA protein assay kit. BCA (bicinchoninic acid)

\subsection{Cell viability}

Cell viability is assessed by MTT (3-(4,5-dimethylthiazol-2-yl)-2,5-diphenyltetrazolium bromide) assay as described [17]. MTT solution is added to the culture medium $(500 \mu \mathrm{g} / \mathrm{ml}$ final concentrations $), 4 \mathrm{~h}$ before the end of treatment and the reaction is stopped by the addition of $100 \mu \mathrm{l}$ of DMSO to the cell culture. The absorbance is measured at $560 \mathrm{~nm}$.

\subsection{Cell proliferation}

The technique used in the study of the effect of the supernatant squid ink on the proliferation of cancer cells U87, seeded into the wells of a microfiber plate at a rate of $510^{3}$ cells / well in $50 \mu \mathrm{l} \mathrm{MEM} / 10 \% \mathrm{FCS}$ (foetal calf serum) / 5\% $\mathrm{SC}$ (horse serum). After 1 hour incubation, the medium was renewed in the presence of fractions to be tested. Every day, three wells were washed with PBS and the cells were fixed in $1 \%$ glutaraldehyde and stored in PBS. At the end of the week, the cells were stained with $0.1 \%$ crystal violet and quantified by measuring the absorbance at $560 \mathrm{~nm}$. 


\section{Statistical study}

Statistical analyzes were performed using Excel 2007 on a Windows XP software. The statistical tests used are F-test and the Fisher Student test T. This analysis is reinforced by the use of SAS software (1989). During the study of the biological activities of the squid ink, all data are expressed as mean \pm standard error of the mean (SEM) of at least 3 independent experiments. Statistical differences were evaluated by 1-way ANOVA followed by Turkey's test using commercially available software (SPSS 17.0; SPSS Inc; Chicago, III). P values $<0.05$ were statistically significant.

\section{Results}

Nutritional analyzes were conducted on organs studied in fresh and cooked solid viscera most consumed in Tunisia (male gonads, nidamental glands, hepatopancreas and squid ink) and represented in Table1 . Results are expressed as \% with the exception of energetic values expressed in kcal.

\subsection{Relative humidity}

Our results report in (Figure 1a), show that male gonads and fresh nidamental glands $(78.47 \pm 1.51$ and $79.09 \pm$ $1.36 \%)$, are richer in water than hepatopancreas male and female $(56.99 \pm 0.80$ and $49.24 \pm 1.22 \%)$, the difference is significant ( $\mathrm{p}<0.05)$. Relative humidity is also important at the ink fresh cuttlefish male and female respectively (61.66 \pm 0.75 and $66.12 \pm 1.74 \%$ ) (Figure 2a). Sex and cooking only decrease slightly water content. The difference is not significant $(\mathrm{p}=0.073)$.

\subsection{Total ash}

Figure (1b) shows that fresh hepatopancreas male $(1.24 \pm 0.04 \%)$, contains less minerals than nidamental glands $(1.62 \pm$ $0.16 \%)$, male gonads $(1,71 \pm 0.08 \%)$ and female hepatopancreas $(1.99 \pm 0.03 \%)$. The difference was not significant between these bodies $(\mathrm{p}=0.08)$. Percentages of minerals uncooked ink in males and females are higher respectively $(5.00 \pm 0.14 \% 5.24 \pm 0.36 \%)$ These percentages are not affected by cooking (Figure $2 \mathbf{b})$.

\subsection{Lipids or fat}

Percentages of fat in fresh hepatopancreas male and female $(7.14 \pm 0.3 \%$ and $6.53 \pm 0.40 \%)$ are elevated compared to male gonads and nidamental glands respectively $(0,72 \pm 0.04 \%$ and $0.98 \pm 0.13 \%)$. The difference is significant between these organs $(\mathrm{p}<0.05)$, (Figure1c). Fresh inks male and female also contain an important percentage of fat respectively $(3.47 \pm 0.35 \%$ and $3.33 \pm 0.48 \%)$. Cooking reduces not significantly the fat content of these organs $(\mathrm{p}=0.085)$, (Figure 2c).

\subsection{Protein}

Protein levels (Figure 1d) show that they are also higher in male's gonads, nidamental glands and hepatopancreas male and female. They correspond to the fresh organs respectively $(15.52 \pm 0.50,16.72 \pm 0.69 \% ; 16.74 \pm 0.67$ and $18.40 \pm$ $0.85 \%)$. The difference is not significant between the different organs $(\mathrm{p}=0.082)$. Fresh inks female and male cuttlefish are also rich in protein and have the respective percentages (18.71 \pm 0.72 and $15.85 \pm 0.88 \%)$. Sex and cooking increase not significantly this common protein content in solid viscera and ink $(\mathrm{p}=0.075)$, (Figure $2 \mathbf{d})$.

\subsection{Carbohydrates}

As for fat, fresh hepatopancreas male and female are also rich in carbohydrate $(18.33 \pm 1.08$ and $24.27 \pm 0.38)$, compared to the male gonad and fresh gland nidamental with the respective percentages $(3.63 \pm 0.37$ and $2.90 \pm 0.27 \%)$. Neither sex nor cooking has any influence on the content of these bodies' carbohydrates, (Figure 1e).

The Figure 2e shows that fresh ink male and female contain less important percentages of carbohydrates $(9.66 \pm 0.34$ and $10.58 \pm 0.59 \%)$. Cooking does not reduce the content of this organ.

\subsection{Energy value}

The energy value of fresh organs is higher in the female and male hepatopancreas $(230.04 \pm 1.23$ and $206.85 \pm 1.58$ $\mathrm{kcal})$, lower level in male gonad $(125.53 \pm 1.24 \mathrm{Kcal})$ and nidamental gland $(119.72 \pm 1.33 \mathrm{Kcal})$. The difference is significant between these organs $(\mathrm{p}<0.05)$. The energy values of fresh squid ink male and female are also high $(133.13 \pm 1.38$ and $148.67 \pm 1.40 \mathrm{kcal})$. 
Sex and cooking did not reduce significantly the energy value of these organs $(\mathrm{p}=0,068)$, (Figure2f).

\subsection{Proteins extraction}

Peptide concentration was determined from a standard curve previously prepared. Protein concentration of Cuttlefish ink Sepia officinalis used during all experiments is $187,69 \mathrm{mg} / \mathrm{ml}$.

\subsection{Cell viability}

Cytotoxicity analysis is carried out to verify if Cuttlefish ink extract from Sepia officinalis is able to produce lethal effect on human Glioblastoma cell line U87. Cells remained adherent presented a normal morphology after treatment until10 $\mu \mathrm{g} / \mathrm{ml}$. Moreover, cell viability, estimated after $5 \mathrm{~h}$ period treatment, was always less than $50 \%$ at the concentration of $20 \mu \mathrm{g} / \mathrm{ml}$ and less than $40 \%$ at the concentration of $30 \mu \mathrm{g} / \mathrm{ml}$. Figure 3. The difference is significant between the concentration treatments $(\mathrm{p}<0,005)$, showing that Cuttlefish ink extract from Sepia officinalis is cytotoxic starting $20 \mu \mathrm{g} / \mathrm{ml}$ dose.

\subsection{Cell proliferation}

The supernatant cuttlefish Sepia officinalis ink have shown a cytotoxic effect on cancer cells U87. To get an idea on the anti-tumor activity of this ink, we have tested the effect of this supernatant at different doses on cell proliferation of cancer cells incubated U87.

Our results show that supernatant cuttlefish ink increasing concentrations does not block proliferation of cancer cells U87 during 4 days of incubation Figure 4.

Table 1: Summary of Different Nutritional Values Studied: Relative Humidity in\% Total Ash In\% Fat In\%, Proteins In\%, Carbohydrates In\% Energy Value in Kcal. (1) Male, (2) Female, (F) Fresh (C) Cooked.

\begin{tabular}{|c|c|c|c|c|}
\hline & Male Gonade & Nidamental Glande & Hépato-Pancreas & Squid Ink \\
\hline \multirow{4}{*}{ Relative Humidity \% } & & & F-1-56,99 $\pm 0,80$ & F-1-61,66 $\pm 0,75$ \\
\hline & F-1- $78,47 \pm 1,51$ & F-2- 79,09 $\pm 1,36$ & $\mathrm{~F}-2-49,24 \pm 1,22$ & F-2-66,12 $\pm 1,74$ \\
\hline & \multirow[t]{3}{*}{ C- $1-74,21 \pm 1,06$} & \multirow[t]{3}{*}{ C-2- 75,64 $\pm 2,28$} & C-1-49,09 $\pm 1,39$ & C-1-58,21 $\pm 1,12$ \\
\hline & & & C-2-36,61 $\pm 1,22$ & C-2-64,54 $\pm 1,24$ \\
\hline \multirow{5}{*}{ Total Asch \% } & & & F-1- 1,24 $\pm 0,04$ & $\mathrm{~F}-1-5,00 \pm 0,14$ \\
\hline & \multirow{4}{*}{$\begin{array}{l}F-1-1, / 1 \pm 0,08 \\
C-1-2,03 \pm 0,13\end{array}$} & F-2- 1,62 $\pm 0,06$ & $\mathrm{~F}-2-1,99 \pm 0,03$ & F-2- 5,24 $\pm 0,36$ \\
\hline & & \multirow[t]{3}{*}{ C-2- $2,37 \pm 0,36$} & C- $1-1,36 \pm 1,13$ & $C-1-5,19 \pm 0,16$ \\
\hline & & & C-2- $1,53 \pm 0,16$ & C-2- 5,04 $\pm 0,26$ \\
\hline & & & F-1- 7,14 $\pm 0,30$ & F-1-3,47 $\pm 0,35$ \\
\hline \multirow{3}{*}{ Lipides \% } & F-1 - 0,72 $\pm 0,04$ & F-2- $0,98 \pm 0,13$ & $\mathrm{~F}-2-6,53 \pm 0,40$ & $\mathrm{~F}-2-3,33 \pm 0,48$ \\
\hline & \multirow[t]{2}{*}{$C-1-0,54 \pm 0,06$} & \multirow[t]{2}{*}{$\mathrm{C}-2-0,81 \pm 0,08$} & C-1- $6,03 \pm 0,47$ & $\mathrm{C}-1-2,92 \pm 0,32$ \\
\hline & & & C- $2-5,16 \pm 0,72$ & $\mathrm{C}-2-2,82 \pm 0,67$ \\
\hline \multirow{5}{*}{ Proteins \% } & \multirow{5}{*}{$\begin{array}{l}\text { F-1 - } 15,52 \pm 0,50 \\
C-1-18,05 \pm 1,37\end{array}$} & \multirow{5}{*}{$\begin{array}{l}\text { F-2- } 16,72 \pm 0,69 \\
\text { C-2-19,61 } \pm 0,82\end{array}$} & F-1- 16,74 $\pm 0,67$ & F-1-15,85 $\pm 0,88$ \\
\hline & & & F-2 - $18,40 \pm 0,85$ & F-2 -18,71 $\pm 0,72$ \\
\hline & & & C-1- $18,24 \pm 1,37$ & C-1-16,27 $\pm 1,03$ \\
\hline & & & C-2- $19,14 \pm 1,48$ & C- $2-19,14 \pm 1,48$ \\
\hline & & & F- $1-18,33 \pm 1,08$ & $\mathrm{~F}-1-9,66 \pm 0,34$ \\
\hline \multirow{3}{*}{ Carbohydrates \% } & \multirow{4}{*}{$\begin{array}{l}F-1-3,63 \pm 0,37 \\
C-1-4,22 \pm 0,44\end{array}$} & F-2- 2,90 $\pm 0,27$ & $\mathrm{~F}-2-24,27 \pm 0,38$ & $\mathrm{~F}-2-10,58 \pm 0,59$ \\
\hline & & \multirow[t]{3}{*}{$C-2-4,06 \pm 0,45$} & C- $1-18,99 \pm 1,47$ & C-1-11,48 $\pm 0,92$ \\
\hline & & & C-2- $25,67 \pm 1,28$ & C-2-11,24 $\pm 0,91$ \\
\hline \multirow{4}{*}{ Energy value kcal } & & & F-1-206,85 $\pm 1,58$ & $\mathrm{~F}-1-133,13 \pm 1,38$ \\
\hline & \multirow{3}{*}{$\begin{array}{l}\text { F- } 1-125,53 \pm 1,24 \\
\text { C- } 1-103,04 \pm 1,80\end{array}$} & \multirow{3}{*}{$\begin{array}{l}\text { F-2- } 119,72 \pm 1,33 \\
\text { C-2- } 91,50 \pm 1,53\end{array}$} & F-2 $-230,04 \pm 1,23$ & F-2-148,67 $\pm 1,40$ \\
\hline & & & $C-1-145,65 \pm 2,27$ & C-1-101,81 $\pm 3,42$ \\
\hline & & & C-2- $197,31 \pm 1,57$ & C-2-142,86 $\pm 1,62$ \\
\hline
\end{tabular}




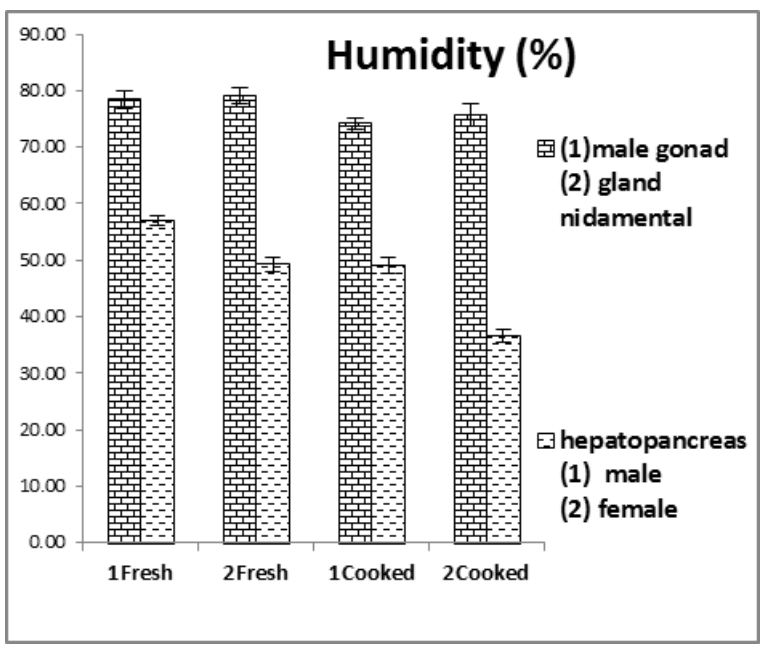

(a)

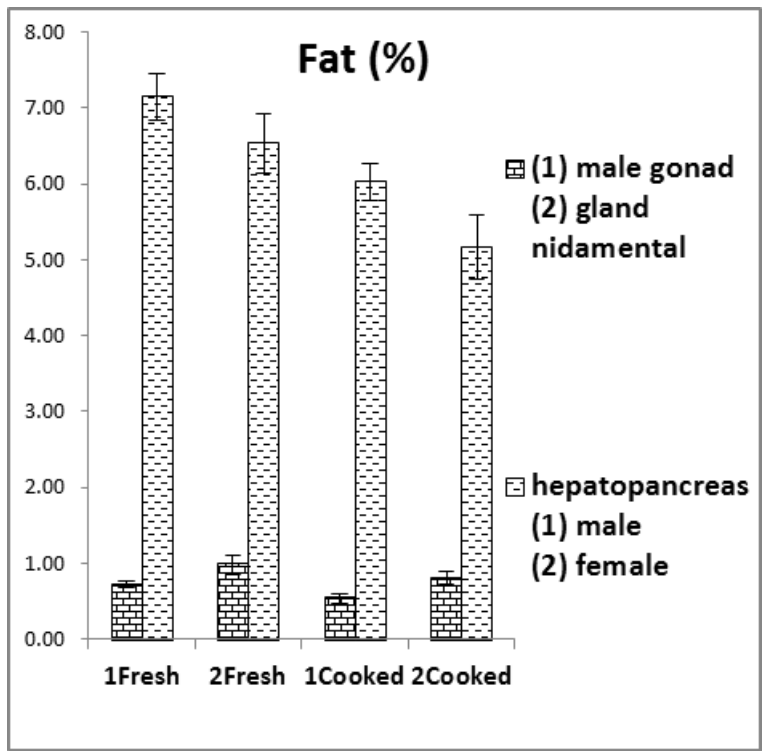

(c)

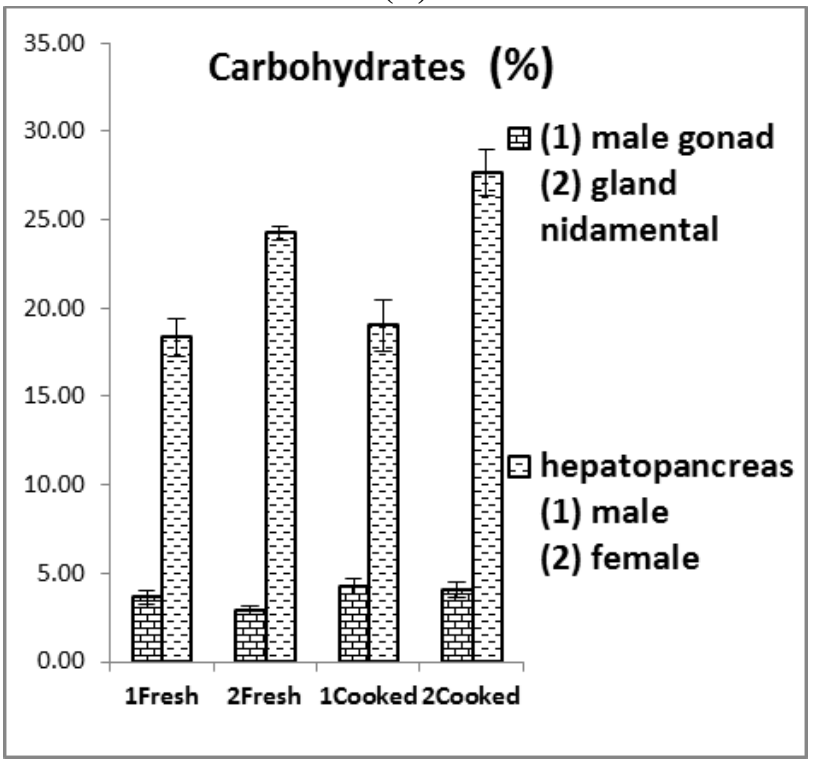

(e)

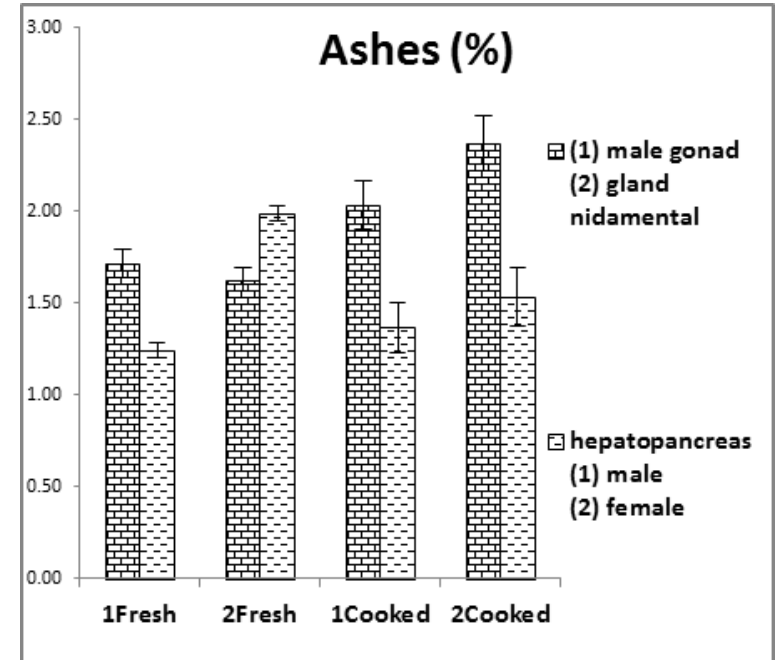

(b)

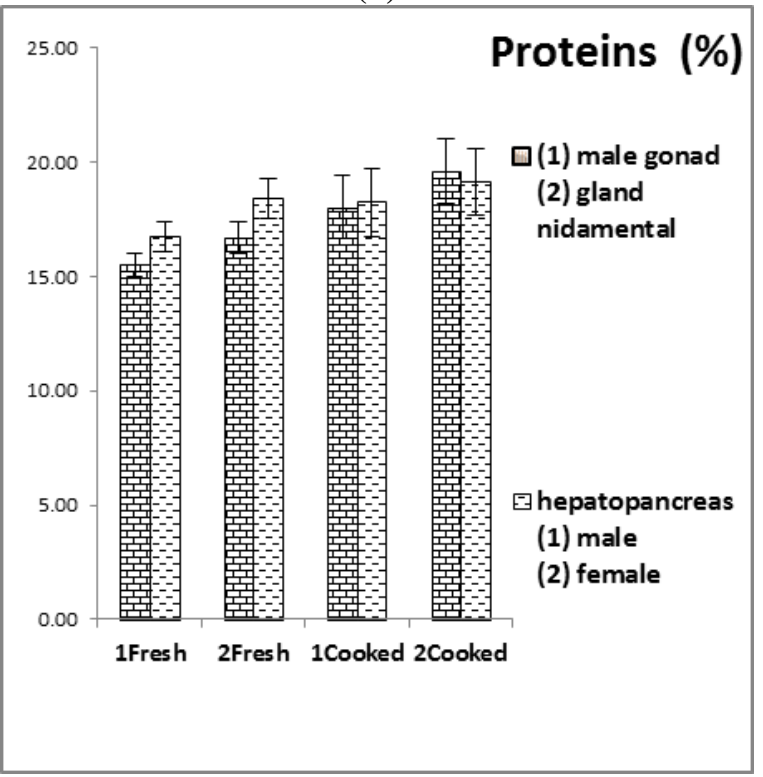

(d)

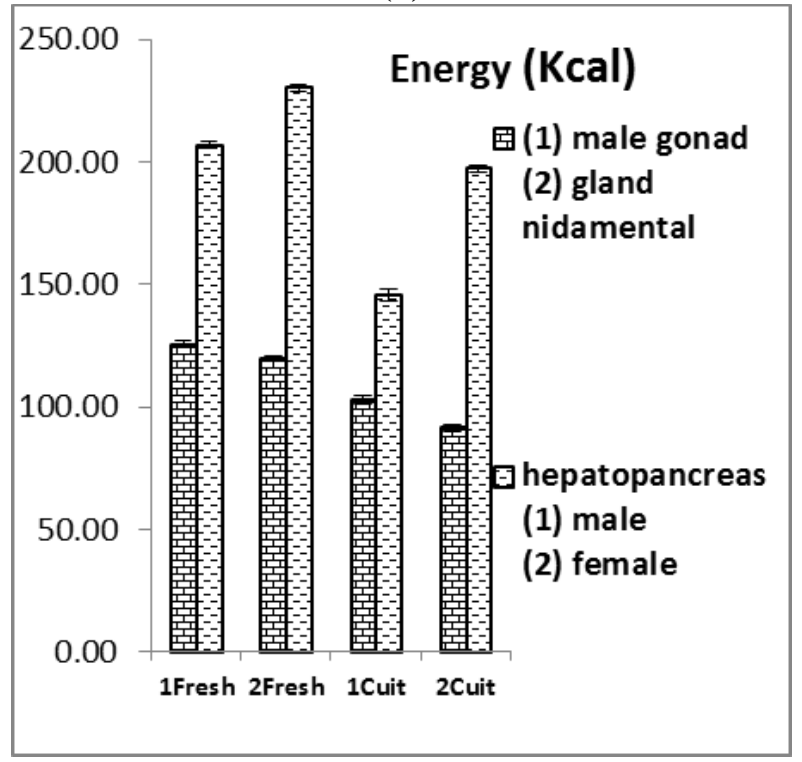

(f)

Fig. 1: Nutritional Values Viscera Studied the Cuttlefish Sepia Officinalis 1- Male Gonad; 2- Nidamental Gland. Hepatopancreas, 1: Male, 2 Female (a)-Relative Humidity in \%, (b)Total Ash in \%, (c) Lipids In \%, (d), Protein In \%,(e), Carbohydrate In \%, (f), Energy Value In Kcal. 


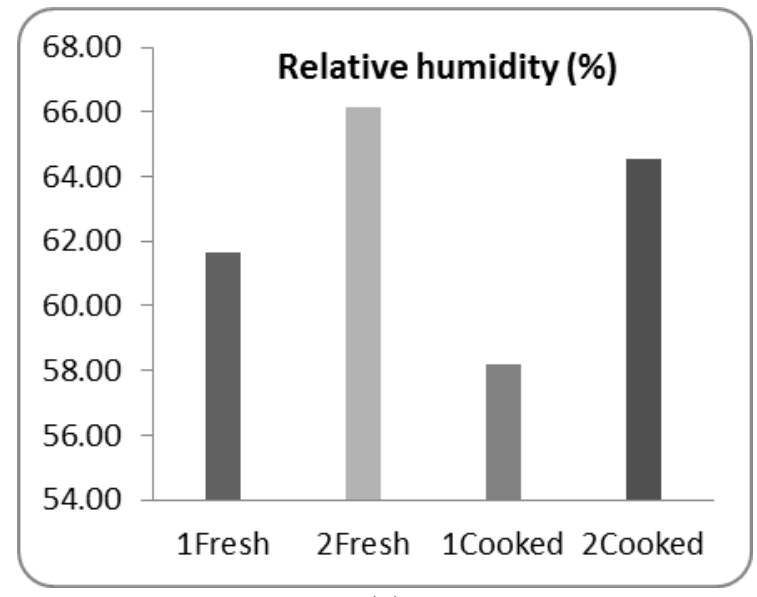

(a)

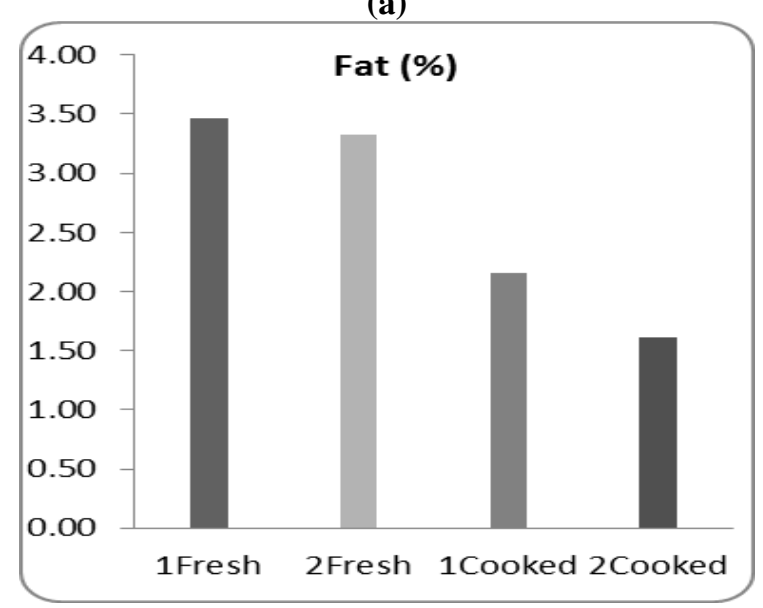

(c)

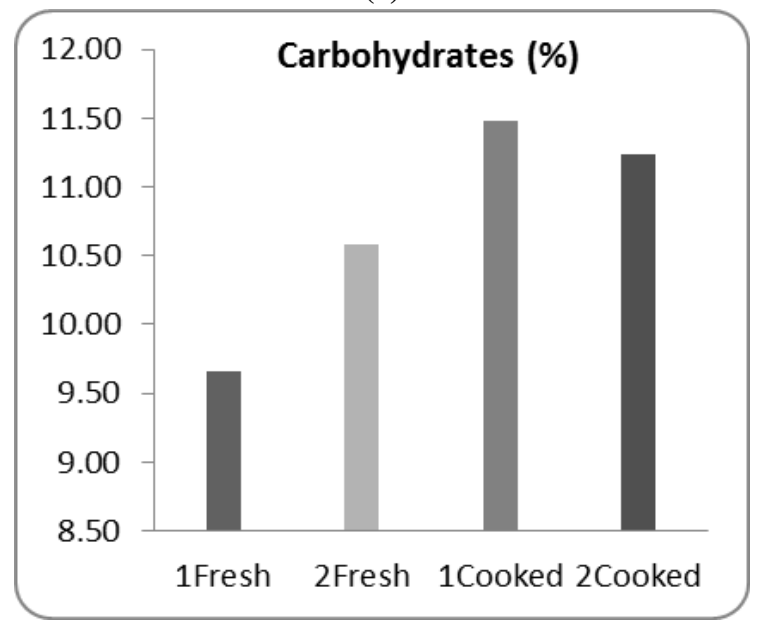

(e)

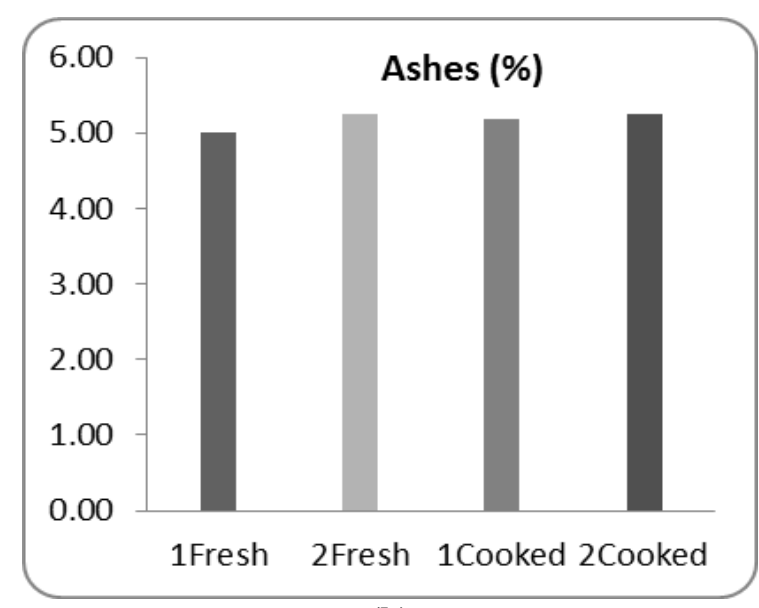

(b)

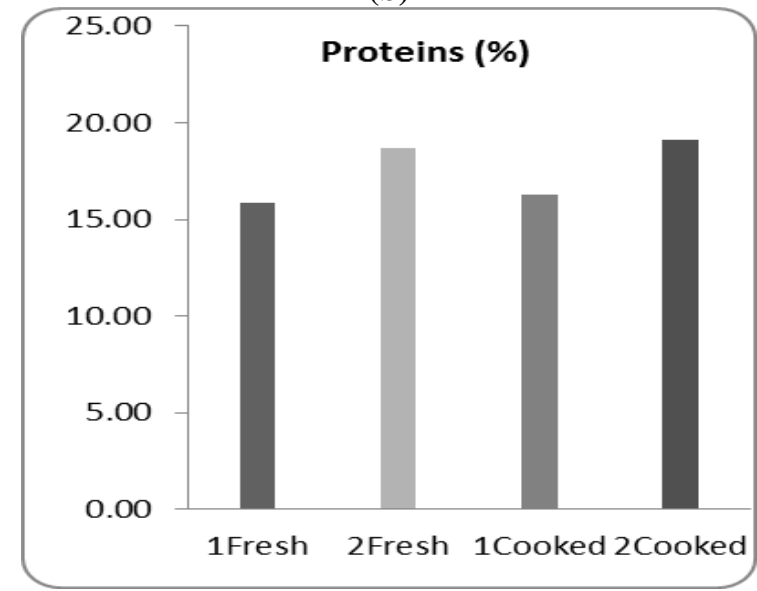

(d)

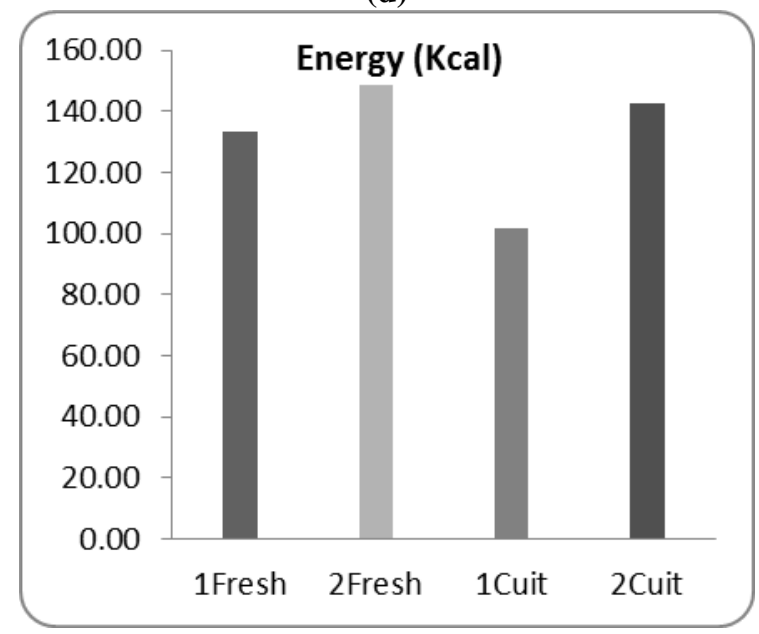

(f)

Fig. 2: Nutritional Values Ink Cuttlefish Sepia Officinalis 1 Male; 2 Female. (a) Relative Humidity in (\%); (b) Total Ash in \% ;(c) Fat in \% ; (d) Proteins in \% ; (e) Carbohydrates in \% ; (f) Energy in Kcal. 


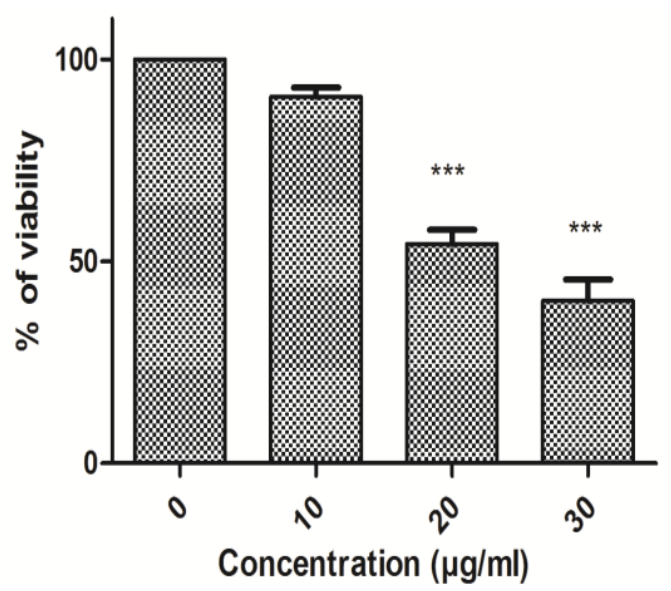

Fig. 3: Dose Dependant Effect of Supernatant Cuttlefish Sepia Officinalis Ink on the Cytotoxicity or Viability of Human Glioblastoma Cells U87

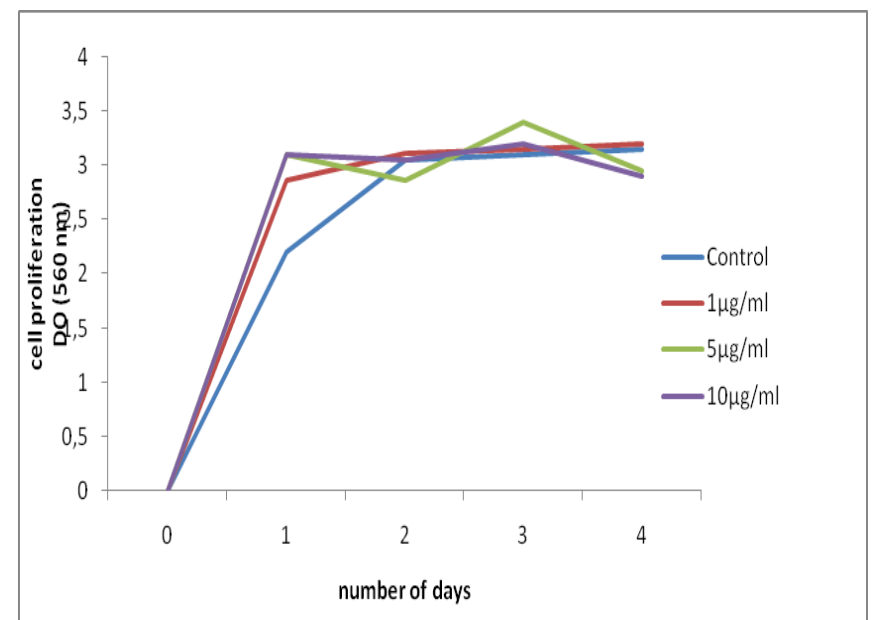

Fig. 4: Glioblastoma Cells U87 Treated or Not (CT) With Increasing Concentrations of supernatant Cuttlefish Sepia Officinalis Ink Does Not Block Proliferation during 4 Days of Incubation

\section{Discussion}

Our study shows that the internal organs as well as fresh ink of Sepia officinalis harvested from the North East sea of Tunisia are rich in water, minerals, proteins but less in fat, in carbohydrates and have substantial energy value. In fact, we found a large quantity of water content, in male gonad and nidamental fresh glands respectively $(78.47 \pm 1.5$ and $79.09 \pm 1.36 \%)$. This amount is little less in hepatopancreas male and female $(56.99 \pm 0.80$ and $49.24 \pm 1.22 \%)$ respectively. These results are consistent with those found in the viscera of cuttlefish caught in Gabes Gulf where water occupied $80 \%$ of the viscera (79\% viscera with ink and $75 \%$ for the viscera without ink). This richness water could be explained by the fact that male gonad and nidamental glands require high water needs to ensure their reproductive and proteolysis functions [12].

The richness of hepatopancreas water in males can be explained by a more intense metabolic activity of hepatic reflecting the rapid shift recognized in the male cephalopod compared to the female one [15].

Relative humidity is also important in the ink of fresh cuttlefish male and female respectively (61.66 \pm 0.75 and $66.12 \pm 1.74 \%$ ). These results agree with those found in fresh ink sepia officinalis (Gabes Gulf), where the percentage of relative humidity was $65.54 \%$ [16]. Indeed, squid ink is composed mainly of water and other volatiles and organic substances as melanines and minerals substances [17]. The high water content of the joint liquid product is used during its ejection on the presence of a predator, constituting a smoke that the animal uses to hide or escape [18].

Mineral content is low in male gonad, nidamental gland and male hepatopancreas respectively $(1.71 \pm 0.08,1.62 \pm 0.06$ and $1.24 \pm 0.04 \%$ ). Total ash is accumulated in the squid ink with the same rates in males and in females, respectively $(5.00 \pm 0.14$ and $5.24 \pm 0.36 \%)$. These values are similar to those found in the literature where the ashes of the cuttlefish vary around $7 \%$ (7, 68\% for the viscera with ink and $7.78 \%$ for the viscera without ink) [19].

Lipids of fresh organs are accumulated with the same percentages for males and females at the hepato-pancreas $(7.14 \pm 0.3$ and $6.53 \pm 0.40 \%)$. They are less in black ink $(3.47 \pm 0.35$ and $3.33 \pm 0.48 \%)$, and with a small percentage in the male gonad, and in the nidamental gland too, respectively $(0.72 \pm 0.04$ and $0.98 \pm 0.13 \%)$. Cooking not significantly reduced the percentage of fat in most organs. Accumulation of these lipids in the hepatopancreas was also observed in another gastropod mollusk Hexaplex trunculus where the percentage of polyunsaturated fatty acids PUFA was $68.2 \%$, 
while saturated fatty acids SFA represented only $334 \%$ of the total fatty acids in the hepatopancreas of this mollusk [20].

These results correlate with those found in the hepathopancréas of the squid where the rate of $\mathrm{C}_{16}$ was $19.23 \%$ [14].Similarly; the solid organs of Sepia officinalis (Gabes Gulf) had a lipid content of $4.8 \pm 0.7 \mathrm{~g} / 100 \mathrm{~g}$ of fresh material distributed in $40 \%$ of saturated fat acid (SFA).

These marine-derived oils are rich in polyunsaturated fatty acids and contribute at the prevention of atherosclerosis through their antioxidant action. They also play a role in the prevention of aging and promote healthy growth and good development of the fetus and infant [21]. This low percentage of lipid could be explained by the fact that the gland contains a big enzyme activity used for melanin genesis [22]. This reason can explain the high rates of protein and the lowest rates of lipids. However, this lipid fraction is potentially important because of its composition as polyunsaturated fatty acid family $\omega 3$ whose interests have been widely described in the literature.

Freshest co-products, solid and liquid, male and female of Sepia officinalis are rich in proteins with percentages ranging from $18.71 \pm 0.72 \%$ in the female ink to $15.52 \pm 0.50 \%$ in the gonad male. These results are consistent with those found in fresh viscera Sepia officinalis (Gabes Gulf) where the percentage of protein in the fraction of the ink was (15.75\%). The essential amino acids showed $40 \%$ with a significant presence of phenylalanine regarded as a precursor of tyrosine the basis for the synthesis of eumelanin, providing the black squid color. [23]. Similarly, the protein content of the viscera was $17.6 \pm 0.3 \mathrm{~g} / 100 \mathrm{~g}$ of dry matter and the essential amino acids in these organs constitute $36 \%$ of all amino acids [19]. This rapid growth and protein metabolism predominantly involves a high protein turnover and therefore significant proteolyses activities. Indeed, the digestive gland of Sepia officinalis is the seat of intense enzymatic activity, amylase, lipase, protease (trypsin, chymotrypsin and cathepsin), esterase and phosphatase are found in this organ [24], [25].

As for lipids, fresh hepato- pancreas male and female are also rich in carbohydrates $(18.33 \pm 1.08$ and $24.27 \pm 0.38 \%)$ compared to the ink, the fresh gonad male and nidamental gland which present the respective values $(9.66 \pm 0.34$, $3.63 \pm 0.37$ and $2.90 \pm 0.27 \%$ ). The richness of the liver pancreas in carbohydrate could be explained by the important role of this organ in the storage of carbohydrates nutrients as liver in vertebrates.

Similarly nidamental glands use these carbohydrates to form the mass of eggs and to protect gel of eggs [26]. Chemical composition of carbohydrates in fresh ink of sepia officinalis was estimated at $13.75 \%$ [27]. Polysaccharides extracted formed $3.02 \%$ and presented a significant anti-mutagenic activity [28]. Also $0.8 \%$ of carbohydrates in the ink of Octopus vulgarus contained in melanin participated at the inhibition of gastric secretion and the prevention of pyloric ulcer in rats [29]. The richness more or less important in protein, lipids and carbohydrate in the viscera and the ink of the studied Sepia officinalis gave substantial energy values ranging from $119.72 \pm 1.33 \mathrm{kcal}$ at the nidamental gland to $230.04 \pm 1,23 \mathrm{kcal}$ at the hepato pancreas female. These values allow us to encourage the consumption of the cuttlefish Sepia officinalis internal organs studied in this work and to use braised cooking over low heat which does not significantly change the nutritional values of these viscera.

Our results show also a cytotoxic effect of cuttlefish ink on line U87 at increasing doses for an incubation time of 5 hours with a concentration higher than $20 \mu \mathrm{g} / \mathrm{ml}$. The IC50 value is $25 \mu \mathrm{g} / \mathrm{ml}$ which may be due to tyrosinase (molecular mass $94 \mathrm{kDa}$ ), responsible for the cephalopod ink toxic effect. Similarly, Ecteinascidin-743, the first anti-cancer drug extracted from marine Tunucate Caribbean (Ecteinascidia horn) was found to be cytotoxic against leukemia cells with IC50 value of $0.5 \mu \mathrm{g} / \mathrm{ml}[30]$.

Our results are consistent with those found by Benkendorff and colleagues. They found no significant effect on cell viability with the extract of the Murex remedy available commercially. In contrast, the Australian mollusk Dicathais orbita egg extract significantly decreased cell viability in most carcinoma cell lines probably due to the presence of brominated indoles known with its anticancer activity [31-32]. In order to colonize new organ sites, tumor cells have to access the lymphatic or blood vessel system, disseminate, extravagate and invade the new organ. These events require cell proliferation too.

Our results show that cellules U87, treated with increasing concentrations of supernatant cuttlefish ink did not significantly block the proliferation during 4 days of incubation $(\mathrm{p}=0.154)$. Our results are consistent with those found in squid ink Ommastresphes bartrami treated with different concentrations on tumour cells Hep G, where cell proliferation was not blocked but induces dose-dependent suppression of invasion and cell migration [33].

\section{Conclusion}

Analysis of the nutritional values of viscera and ink of cuttlefish Sepia officinalis harvested from Tunisian North East Sea, has shown that these organs contain valuable nutritional values with generally non-significant difference between male and female. Fresh edible internal organs are more or less rich in water, minerals, protein, and fat and under in carbohydrates with high calorie energy values. The fresh squid ink virtually unused in our diet also contains a high percentage of water, ash, protein, fat and carbohydrates with valuable energy values. Cooking over low heat seems to have no effect on these nutritional values. These results lead us to encourage the use of these marine-products sepia officinals generally rejected, not only for food but they seems to prevent and reduce the incidence of certain diseases. In 
fact our results show also a cytotoxic effect of cuttlefish ink on line U87 at increasing doses for an incubation time of 5 hours with a concentration higher than $20 \mu \mathrm{g} / \mathrm{ml}$. The IC50 value is $25 \mu \mathrm{g} / \mathrm{ml}$ which may be due to the enzym tyrosinase, responsible for the cephalopod ink toxic. Supernatant of cuttlefish ink Sepia offinalis does not block proliferation of cancer cells U87 during 4 days of incubation. Further analyses are warranted and necessary to substantiate and complete our findings such as the study of the effect of this ink in adhesion and migration of Glioblastoma cells U87.

\section{References}

[1] Lian PZ, Lee C. M and Park E. Characterization of squid-processing byproduct hydrolysate and its potential as aquaculture feed ingredient. J Agric Food Chem, 2005. 53(14): p. 5587-92.

[2] Mai K L, Ai H, Duan Q, Zhan L, Tan B and Liufi, Z. Effects of dietary squid viscera meal on growth and cadmium accumulation in tissues of Japanesse seabass, Lateolabrax japonicus (cuvier 1828) Aquaculture Res, 2006. 37: p. 1063-1069.

[3] Balti R. Comparative Study on Biochemical Properties and Antioxidative Activity of Cuttlefish (Sepia officinalis) Protein Hydrolysates Produced by Alcalase and Bacillus licheniformis NH1 Proteases. J Amino Acids, 2011. Vol. 45: p. 107179.

[4] Venugopal V, and Shahidi F. Value-added products from underutilized fish species. Crit Rev Food Sci Nutr, 1995. Vol 5: p. 431-53.

[5] Diniz F. M. and M. Martin A. Influence of process variables on the hydrolysis of shark muscle protein. Food Science and Technology International, 1998. Vol.2: p. 91-98.

[6] Zhong JP, Wang G, Shang JH, Pan JQ, Yan Huan KL and Lieu HZ. Pretective effects of squid ink esrect towards hemopoietic injuries induced by cyclophosphamine. Mar Drugs, 2008. Vol.7: p. 9-18.

[7] Kicklighter CE, Shabani S, Johnson PM and Derby CD. Sea hares use novel antipredatory chemical defenses. Curr Biol, 2005. Vol. 15: p. 549-554.

[8] Carefoot TH, Pennings SC and Dankoa JP. Atest of novel fonctions of the ink of sea hares. J Exp Mar Biol Ecol, 1999. Vol. 234: p. 185-197.

[9] Lu T, and Gao CY. Effects of elevating leukocyte number of cuttlefish ink. Pract J Integ Chin Mod 1995. Vol.3: p.163-164.

[10] Lei M, Wang J, Wang Y, Pang L, Xu W and Xu C. Study of the radioprotective effect of cuttlefish ink on hemopoitic injury. Asia Pac J Clin Nutr, 2007. Vol. 16: p. 239-243.

[11] Sadok S, Abdelmouleh Aand ElAbed A. Combined effect Sepia soaking and tempeture on the shelf life of peeled shrimps Peneaus kerathurus. Food Chem, 2004. Vol. 88: p.115-122.

[12] Senan VP, George MC, Joseph SM, Pllai D, Nair JR and Sherief PM. Anti proliferative effect of cuttlefish ink extract on chiken embryofibroblast. Prceedings of the national seminar on new frontiers in marine bioscience Research, january; 2004. Vol. 22: p. 35-39.

[13] Folch J, Lees M and Sloane Stanley GH. A simple method for the isolation and purification of total lipides from animal tissues. J Biol Chem, 1957. 226(1): p. 497-509

[14] crooke W M, Simpson W E. Determination of ammonium in Kjeldhal digests of crops by an automated procedure. J.Agric.Food chemestery, 1971.Vol. 27: p. 1256-1262.

[15] Takaya Y, Uchisawa H, Matsue H, Okuzaki B, Narumi F, Sasaki J.and Ishida K. An investigation of the antitumor peptidoglycan fraction from squid ink. Biological \& pharmaceutical bulletin, 1994.Vol.17: p 846-849.

[16] Defilles, C., Lissitzky, J. C., Montero, M. P., Andre, F., Prevot, C., Delamarre, E., Marrakchi, N., Luis, J., and Rigot, V. alphavbeta5/beta6 integrin suppression leads to a stimulation of alpha2beta1 dependent cell migration resistant to PI3K/Akt inhibition. Experimental cell research, 2009. Vol.31: p. 1840- 1849 .

[17] Mosmann, T. Rapid colorimetric assay for cellular growth and survival: application to proliferation and cytotoxicity assays. Journal of immunological methods, 1983. Vol.65: p.55-63

[18] Rigot, V., Lehmann, M., Andre, F., Daemi, N., Marvaldi, J., and Luis, J. Integrin ligation and PKC activation are required for migration of colon carcinoma cells. Journal of cell science, 1998. Vol.111: p. 3119-3127

[19] Kechaou E S. Enzymatic hydrolysis of cuttlefish (Sepia officinalis) and sardine (Sardina pilchardus) viscera using commercial proteases: effects on lipid distribution and amino acid composition. J Biosci Bioeng, 2009. Vol.107: p. 158-164.

[20] Balti R. Cathepsin D from the Hepatopancreas of the Cuttlefish (Sepia officinalis): Purification and Characterization. J Agric Food Chem, 2010. Vol.58: p. 10623-10630.

[21] Shyla G. Liver oil of pharaoh cuttlefish Sepia pharaonis Ehrenberg, 1831 as a lipid source in the feed of giant freshwater prawn, Macrobrachium rosenbergii (De Man 1879). Aquaculture Nutrition, 2009. Vol. 3: p. 273-281.

[22] Castro B G, Garrido JL and. Sotelo C G. Changes in Composition of Digestive Gland and Mantle Muscle of the Cuttlefish Sepia-Officinalis during Starvation. Marine Biology, 1992. Vol.114.p. 11-20.

[23] Neifar A. Physicochemical characterization of Sepia officinalis ink and the effects of storage conditions on the coagulation process. Journal of the Marine Biological Association of the United Kingdom, 2009. Vol.4: p. 803-807.

[24] Van den Branted C, Richard A, Lemaire Jand Decleir A. Nidamentalaccessorygland of sepia officinalis. Biochemical analysis of symbiotic bacteria pigment. Ann Soc.r. zoolbeig . Brussels, 1979.Vol:108. p.123-129.

[25] Van den Branted C, Gills M and Richard A. Carotenoid producing bacteria in the accessory nidamental gland of sepia officinalis. Biochemical. Comp. Physiol analysis, 1980.Vol:66. p.331-334

[26] Barbieri E, Paster BJ, Hughs D, Zerek L, Moser DP, Tesk A and Sogin ML. Phylogenetic characterization of epibiotic bacteria in the accessory nidamental gland and egg capsules of the squid Loligo pealei ( cephalopoda: Loliginidae). Environ . Micribiol, 2001. Vol: 3. P151167.

[27] Hattner. R S. Electrochemical determination of apparent ionized serum calcium using a calcium-selective electrode: the method and values in normal humans and a comparison to total serum calcium. Clin Chim Acta, 1970. Vol.1: p. 67-75.

[28] Adamo S A. Signaling to the enemy? Body pattern expression and its response to external cues during hunting in the cuttlefish Sepia officinalis (Cephalopoda). Biol Bull, 2006. Vol .3: p. 192-200.

[29] Vas-Pires P and Barbosa A. Sensory microbiological, physical and nutritional propertis of iced whole common octopus (Octopus vulgaris). Lebensm-Wiss.U. Technol, 2004. Vol 62: p.3298-3307.

[30] Rinehart, KL, Holt, T G, Fregeau, N L, Keifer, PA, Wilson, GR, Perun, TJ, Sakai R Thompson, A G, Stroh, J G, Shield, LS and Et Al. Bioactive compounds from aquatic and terrestrial sources. Journal of natural products, 1990. Vo:53.p. 771-792.

[31] Benkendorff, K. Natural Product Research in the Australian Marine Invertebrate Dicathais orbita. Marine drugs, 2013. Vol.11: p. 1370-1398 .

[32] Benkendorff K Mciver CM., and Abbott C A. Bioactivity of the Murex Homeopathic Remedy and of Extracts from an Australian Muricid Mollusc against Human Cancer Cells. Evidence-based complementary and alternative medicine, 2011 : CAM 879585.

[33] Chen S, Wang J, Xue C, Sun B, Xue Y and Chai W. Sulfation of a squid ink polysaccaharide and its inhibitory effect on tumor cell metastasis.Carbohydrate polymers. J Biol Chem, 2010. Vol. 81: p. 560-566. 